\title{
Scaly Skin Eruption
}

National Cancer Institute

\section{Source}

National Cancer Institute. Scaly Skin Eruption. NCI Thesaurus. Code C39622.

Peeling skin patches. Causes include psoriasis, eczema, and sunburns. 